\title{
Enhanced catalytic degradation of ciprofloxacin over Ce-doped OMS-2 microspheres
}

\author{
Lili Zhang, Jinjun Tu, Lai Lyu, Chun Hu* \\ Key Laboratory of Drinking Water Science and Technology, Research Center for Eco-Environmental Sciences, Chinese Academy of Sciences, Beijing 100085,
} China

\section{A R T I C L E I N F O}

\section{Article history:}

Received 17 April 2015

Received in revised form 15 July 2015

Accepted 14 August 2015

Available online 20 August 2015

\section{Keywords:}

Ce-OMS-2

Catalytic oxidation

Ciprofloxacin

$\mathrm{O}_{2}{ }^{\cdot-}$ radicals

\begin{abstract}
A B S T R A C T
A novel Ce-doped manganese oxide octahedral molecular sieve (Ce-OMS-2) was prepared by a reflux method and characterized by field emission scanning electron microscope, high resolution transmission electron microscopy, Fourier-transform infrared spectra, nitrogen adsorption/desorption isotherms, Xray diffraction and $\mathrm{X}$-ray photoelectron spectroscopy. The $\mathrm{Ce}(0.48)-\mathrm{OMS}-2$ with $\mathrm{Ce} / \mathrm{Mn}$ molar ratio of 0.48 was highly effective and stable for the degradation of ciprofloxacin in water. The characterized results indicated that Ce mainly entered the tunnel structure of OMS-2, significantly increasing the BET surface area from $72 \mathrm{~m}^{2} / \mathrm{g}$ for OMS-2 to $304 \mathrm{~m}^{2} / \mathrm{g}$ for $\mathrm{Ce}(0.48)-O M S-2$. Moreover, the surface oxygen defects and surface labile oxygen significantly increased after the introduction of Ce into OMS-2, being determined by the $01 \mathrm{~s}$ spectra and $\mathrm{O}_{2}$-TPD analysis. The ESR and activity tests under different conditions suggested that the reduced manganese $\mathrm{Mn}(\mathrm{II})$ could interact with surface labile oxygen to form $\mathrm{O}_{2}{ }^{-}$- and $\mathrm{Mn}(\mathrm{IV})$, resulting in the high activity of $\mathrm{Ce}(0.48)$-OMS-2 to degrade the piperazine ring and the quinolone moiety of CIP into small molecular products. Simultaneously, the release of $\mathrm{Mn}(\mathrm{II})$ was inhibited by the electron transfer process on the micro-interface of $\mathrm{Ce}(0.48)$-OMS- 2 .
\end{abstract}

(c) 2015 Elsevier B.V. All rights reserved.

\section{Introduction}

Numerous studies around the world have demonstrated the presence of pharmaceutical compounds in waterways, as they are hardly biodegradable and usually escape conventional wastewater treatment plants (WWTPs) [1]. The result of constant discharges of these chemicals in the environment may lead to public health problems even though the concentration is low, ranging from micro- to nanograms per liter [2]. Ciprofloxacin (CIP), for example, a fluoroquinolone antibiotic, has been detected at concentrations up to $31 \mathrm{mg} \mathrm{L}^{-1}$ in waste effluents from pharmaceutical manufacturers [3]. Therefore, effective treatment methods for these pharmaceuticals need to be explored. Catalytic oxidation is one of the most attractive technologies for the removal of residual pharmaceuticals in water and wastewaters.

Synthetic cryptomelane, known as octahedral molecular sieve (OMS-2), has been reported as an efficient catalyst in many oxidation reactions [4,5]. OMS-2 is a porous manganese oxide with a

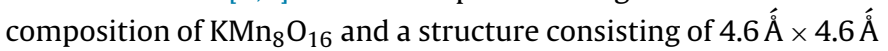

\footnotetext{
* Corresponding author. Fax: +86 1062923541

E-mail address: huchun@rcees.ac.cn (C. Hu).
}

tunnels due to a $2 \times 2$ arrangement of edge-shared $\mathrm{MnO}_{6}$ octahedra [6]. Potassium ions reside in the tunnels to keep the stability and charge balance on structure of OMS-2. The average manganese oxidation state is less than 4, reflecting mixed valence from $\mathrm{Mn}(\mathrm{IV})$ and minor amounts of $\mathrm{Mn}$ (III/II) [7,8]. The different oxidation states of manganese provide OMS-2 with significant advantages as a redox medium for the removal of organic pollutants. To improve the catalytic activity, OMS-2 was usually doped by foreign metal ions, such as $\mathrm{Fe}^{3+}, \mathrm{Co}^{2+}, \mathrm{Cu}^{2+}, \mathrm{V}^{5+}$ and $\mathrm{Mo}^{6+}[9,10]$. The metal dopants can be loaded on the surface, incorporated into the framework, or entered into the tunnel of OMS-2 by different preparation processes, such as ball milling, impregnation, reflux, and hydrothermal methods $[11,12]$. Inclusion of foreign metals in the framework or tunnel structure could lead to increase in defects inside the catalyst surface thereby creating more number of active sites [13,14]. Cerium (Ce) with a redox cycle between the +3 and +4 states can be manipulated to create efficient catalysts. Ce incorporated OMS-2 has been synthesized by ion exchange process and wet impregnation method, and used in gas phase decomposition of cyclohexanol [15] and removal of acetaldehyde [16]. The stability of metal-doped OMS-2 in water phase reaction could be more complicated than that in gas phase reaction. The oxidation of organic compounds by metal-doped OMS-2 in aqueous solution was often followed by the release of organic oxidation products, $\mathrm{Mn}(\mathrm{II})$ and/or other 
metal dopants. This paper intends to investigate the performance of Ce-doped OMS-2 for wastewater treatment through catalytic oxidation at room temperature and neutral $\mathrm{pH}$.

In the present study, Ce-doped OMS-2(Ce-OMS-2) was prepared with a reflux method. The effects of Ce doping on the morphology, structure and catalytic performance were systematically studied by multi-technologies. It was found that $\mathrm{Ce}(0.48)-\mathrm{OMS}-2$ microspheres were highly effective for the degradation of the antibiotic $\mathrm{CIP}$, and simultaneously the release of $\mathrm{Mn}$ (II) was much lower than the EU directives $\left(<0.05 \mathrm{mg} \mathrm{L}^{-1}\right)$. The degradation of CIP came from both $\mathrm{Mn}(\mathrm{IV})$ in $\mathrm{Ce}-\mathrm{OMS}-2$ and $\mathrm{O}_{2}{ }^{-}$- generated by the reoxidation of $\mathrm{Mn}(\mathrm{II})$ by surface labile oxygen, inhibiting $\mathrm{Mn}(\mathrm{II})$ release. The catalytic mechanism was discussed in detail.

\section{Experimental}

\subsection{Materials}

Cerium nitrate $\left(\mathrm{Ce}\left(\mathrm{NO}_{3}\right)_{3} \cdot 6 \mathrm{H}_{2} \mathrm{O}\right)$ and nitric acid $\left(\mathrm{HNO}_{3}\right)$ were purchased from Sinopharm Chemical Reagent Co., Ltd. Potassium permanganate $\left(\mathrm{KMnO}_{4}\right)$ and manganese sulfate $\left(\mathrm{MnSO}_{4} \cdot \mathrm{H}_{2} \mathrm{O}\right)$ were supplied by Beijing Chemical Reagent Company. Ciprofloxacin (CIP) was obtained from Sigma. All chemicals were at least analytical grade.

\subsection{Preparation of catalysts}

Ce-OMS-2 was synthesized using a reflux method. In a typical procedure, $18.6 \mathrm{mmol} \mathrm{KMnO}_{4}$ was dissolved in $50 \mathrm{~mL}$ of deionized water to form solution A. Then, $26.0 \mathrm{mmol} \mathrm{MnSO} \cdot \mathrm{H}_{2} \mathrm{O}$ and a certain amount of $\mathrm{Ce}\left(\mathrm{NO}_{3}\right)_{3} \cdot 6 \mathrm{H}_{2} \mathrm{O}$ were dissolved in $15 \mathrm{~mL}$ of $\mathrm{HNO}_{3}(10 \%$, $\mathrm{v} / \mathrm{v}$ ) solution to form solution $\mathrm{B}$. Next, solution A was added slowly to solution B under vigorous stirring to obtain brown slurry. The brown slurry was then refluxed for $24 \mathrm{~h}$. After natural cooling, the obtained solids were filtered, washed with deionized water and dried at $100^{\circ} \mathrm{C}$. The synthesized samples were denoted as OMS-2, $\mathrm{Ce}(0.06)-O M S-2$, $\mathrm{Ce}(0.48)-O M S-2$, and $\mathrm{Ce}(0.96)-O M S-2$, where the number referred to the $\mathrm{Ce} / \mathrm{Mn}$ molar ratio in the precursor solution of $0,0.06,0.48$, and 0.96 , respectively.

\subsection{Characterization}

Morphological studies were carried out using a field emission scanning electron microscope (FESEM, Hitachi, SU8020). The high resolution transmission electron microscopy (HRTEM) images of the samples were obtained using a JEOL-2010 TEM with an acceleration voltage of $200 \mathrm{kV}$. The Brunauer-Emmett-Teller (BET) surface area of various samples was determined by nitrogen adsorption/desorption experiments using a surface area and porosity analyzer (ASAP 2020HD88). Powder X-ray diffraction (XRD) patterns were recorded using a Scintag-XDS-2000 diffractometer with $\mathrm{Cu} \mathrm{K} \alpha$ radiation $(\lambda=1.540598 \AA$ ). Fourier-transform infrared (FTIR) spectra were obtained using a Bruker Tensor 27 FTIR Spectrophotometer. For FTIR, powdered specimens were diluted with $\mathrm{KBr}$ at a ratio of $1: 100$, and pressed into a pellet. X-ray photoelectron spectroscopy (XPS) data were measured via an AXIS-Ultra instrument from Kratos using monochromatic Al K $\alpha$ radiation $(225 \mathrm{~W}, 15 \mathrm{~mA}$, $15 \mathrm{kV}$ ) and low-energy electron flooding for charge compensation. To compensate for surface charge effects, binding energies were calibrated using the $\mathrm{C} 1 \mathrm{~s}$ hydrocarbon peak at $284.8 \mathrm{eV}$. Temperature programmed desorption of oxygen $\left(\mathrm{O}_{2}\right.$-TPD) experiments were performed on a ChemBET Pulsar TPD chemical adsorption instrument equipped with thermal conductivity detector (TCD). The samples $(0.1 \mathrm{~g})$ were pretreated at $110^{\circ} \mathrm{C}$ for $1 \mathrm{~h}$ in helium to remove surface $\mathrm{H}_{2} \mathrm{O}$ and physically adsorbed $\mathrm{O}_{2}$, then heated from $100{ }^{\circ} \mathrm{C}$ to $900^{\circ} \mathrm{C}$ at a rate of $10^{\circ} \mathrm{C} \mathrm{min}^{-1}$ in helium to record the TPD spectra. ESR spectra were obtained using a Bruker model ESP 300E electron paramagnetic resonance spectrometer.

\subsection{Procedures and analysis}

Unless indicated otherwise, $0.1 \mathrm{~g} \mathrm{~L}^{-1}$ catalysts were dispersed in $10 \mathrm{mg} \mathrm{L}^{-1} \mathrm{CIP}$ solution. The suspension was constantly stirred in dark at room temperature at $\mathrm{pH}$ 7.0. At given time intervals, suspension samples were withdrawn and filtered to remove powders for analysis. The concentration of CIP was measured using highperformance liquid chromatography (1200 series; Agilent) with a Zorbax SB-Aq column ( $5 \mu \mathrm{m}, 4.6 \times 250 \mathrm{~mm}$; Agilent). The analysis was carried out at $278 \mathrm{~nm}$ using a $20 / 80 \% \mathrm{v} / \mathrm{v}$ mixture of acetonitrile/phosphoric acid ( $\mathrm{pH} 2.5$ ) as mobile phase. The measurement of short-chain organic acids was conducted using a Dionex model ICS 2000 ion chromatograph (IC) equipped with an IonPac AS11$\mathrm{HC}$ analytical column $(4 \times 250 \mathrm{~mm})$ and using $40 \mathrm{mM} \mathrm{KOH}$ as an eluent. For the identification of CIP degradation intermediates in $\mathrm{Ce}(0.48)-O M S-2$ suspension, samples after reaction for $3 \mathrm{~h}$ were filtered and the filtrates were concentrated by solid phase extraction (SPE) method consisting of an Oasis HLB hydrophilic-lipophilic cartridges $(200 \mathrm{mg} / 6 \mathrm{~mL}$ ) (Waters Oasis). The cartridges were initially conditioned with $10 \mathrm{~mL}$ of methanol. $50 \mathrm{~mL}$ sample was loaded onto the cartridges at a $15 \mathrm{~mL} \mathrm{~min}^{-1}$ flow rate. The compounds were then eluted off of the cartridges with $5 \mathrm{~mL}$ methanol and $5 \mathrm{~mL}$ Milli Q water. The eluent was evaporated to dryness under a gentle stream of nitrogen and then reconstituted with $1 \mathrm{~mL}$ of water-methanol mixture $(1: 1 \mathrm{v} / \mathrm{v})$, resulting in 50 -fold concentration of analytes. The samples after concentration were analyzed by ultra high-performance liquid chromatography \& quadrupole time-of-flight mass spectrometer (ACQUITY UPLC/Xevo G2 Q-TOF, Waters), using electrospray ionization (ESI) in positive mode. An ACQUITY UPLC ${ }^{\circledR}$ HSS T3 column $(1.8 \mu \mathrm{m}, 2.1 \times 50 \mathrm{~mm})$ was used with a mobile phase containing water $(0.1 \%$ formic acid $)$ as eluent $A$ and acetonitrile ( $0.1 \%$ formic acid) as eluent $B$. The linear gradient was from $5 \%$ B to $70 \%$ B in $20 \mathrm{~min}, 70 \%$ B to $95 \%$ B in $20-22 \mathrm{~min}$, and then kept isocratic up to $28 \mathrm{~min}$.

To test the stability and recyclability of $\mathrm{Ce}(0.48)-\mathrm{OMS}-2$, the catalyst was filtered, washed with water, and dried at $100^{\circ} \mathrm{C}$. The catalyst was continued to be used in the second cycle. This process was repeated several times.

In addition, the metal content in the material after dissolving by oxalic acid and hydrochloric acid and the released Mn(II) during the reaction were monitored by inductively coupled plasma optical emission spectrometry (ICP-OES) on an Optima 2000 (PerkinElmer, Inc.) instrument.

All of the above experiments were repeated in triplicate and data represented the average of the triplicates with a standard deviation of less than $5 \%$.

\section{Results and discussion}

\subsection{Characterization of catalysts}

The FESEM micrographs of OMS-2 and Ce-OMS-2 are shown in Fig. 1. OMS-2 had a fibrous rod-like morphology, with a fiber length of 1-1.5 $\mathrm{mm}$ (Fig. 1a). Remarkably, with increase of Ce contents, the fiber lengths decreased to ca. $0.1 \mu \mathrm{m}$ for $\mathrm{Ce}(0.06)-\mathrm{OMS}-2$, and clusters were found between these short fibrous rods (Fig. 1b). Further aggregations of fibrous rods with shorter length were observed on $\mathrm{Ce}(0.48)-O M S-2$ to form well-organized microspheres with an average diameter of $0.5 \mu \mathrm{m}$ and rough surface (Fig. 1c). With further increase of Ce content in OMS-2, the surface of microspheres became smooth. And the spherical particles with a smaller diameter (ca. $0.2-0.5 \mu \mathrm{m}$ ) randomly accumulated and partly cracked for 


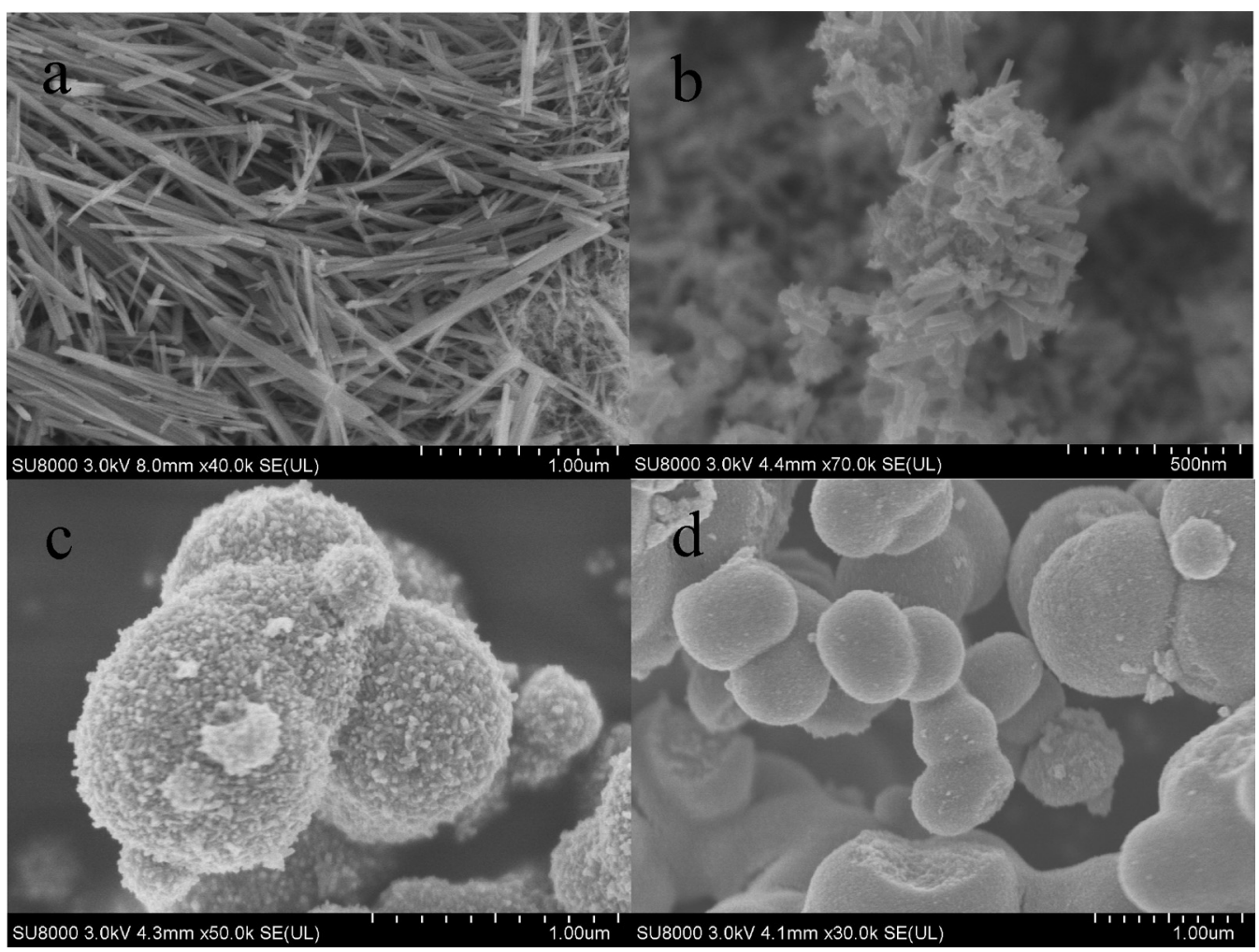

Fig. 1. FESEM images of different samples: (a) OMS-2, (b) Ce(0.06)-OMS-2, (c) Ce(0.48)-OMS-2, and (d) Ce(0.96)-OMS-2.

Ce(0.96)-OMS-2 (Fig. 1d). The inhibitory effects of Ce doping on the fiber length were in agreement with the results observed in Vdoped OMS-2 material by Sun et al. [17], which was attributed to distortion of octahedral units after foreign metal substitution and subsequent introduction of defects.

TEM images in Fig. S1 revealed that OMS-2 was fibrous and $\mathrm{Ce}(0.48)-O M S-2$ had a microsphere morphology, consistent with the results observed with FESEM. A deeper inspection of the microstructures of OMS-2 and Ce(0.48)-OMS-2 using HRTEM showed the presence of lattice fringes at $0.48 \mathrm{~nm}$ corresponded to the (200) D-spacing of OMS-2, whereas Ce(0.48)-OMS-2 had one more lattice fringe space at $0.31 \mathrm{~nm}$ attributed to the (310) plane of OMS-2, confirming the formation of a cryptomelane phase. The crystalline structure of the synthesized samples were shown in Fig. 2. The XRD patterns of the OMS-2 and Ce-OMS-2 samples corresponded to cryptomelane $\left(\mathrm{KMn}_{8} \mathrm{O}_{6}\right.$, JCPDS 42-1348, I4/m tetragonal unit cell) [18]. No additional peaks attributed to $\mathrm{Ce}$ species appeared, suggesting a high dispersion of Ce species on OMS-2 or substitution into the structure. With the increase of Ce doping, the intensity of the peaks decreased and the peak width broadened, indicating the crystallization of Ce-OMS-2 was interfered by Ce doping [10]. The lattice vibrational behavior of the different samples was studied using FTIR spectroscopy to probe the effect of Ce substitution on the spectral features of OMS-2. As shown in Fig. S2, the FTIR spectrum of OMS-2 showed four characteristic bands around $720 \mathrm{~cm}^{-1}, 590 \mathrm{~cm}^{-1}, 530 \mathrm{~cm}^{-1}$, and $470 \mathrm{~cm}^{-1}$ with comparable relative intensities that can be assigned to $\mathrm{Mn}-\mathrm{O}$ lattice vibration modes in $\left[\mathrm{MnO}_{6}\right]$ octahedra [14,19]. Upon doping of Ce into OMS-2 structure, the bands at $530 \mathrm{~cm}^{-1}$ and $470 \mathrm{~cm}^{-1}$ shifted to $537 \mathrm{~cm}^{-1}$ and $481 \mathrm{~cm}^{-1}$, respectively, for Ce(0.06)-OMS2 , whereas the ones at $720 \mathrm{~cm}^{-1}$ and $590 \mathrm{~cm}^{-1}$ did not change in peak position. Moreover, the intensities of the peaks at $720 \mathrm{~cm}^{-1}$, $530 \mathrm{~cm}^{-1}$ and $470 \mathrm{~cm}^{-1}$ significantly deceased after doping. The variation of FTIR spectra indicated the change of $\mathrm{Mn}-\mathrm{O}$ vibrations in octahedral environments after Ce doping. In addition, no peaks

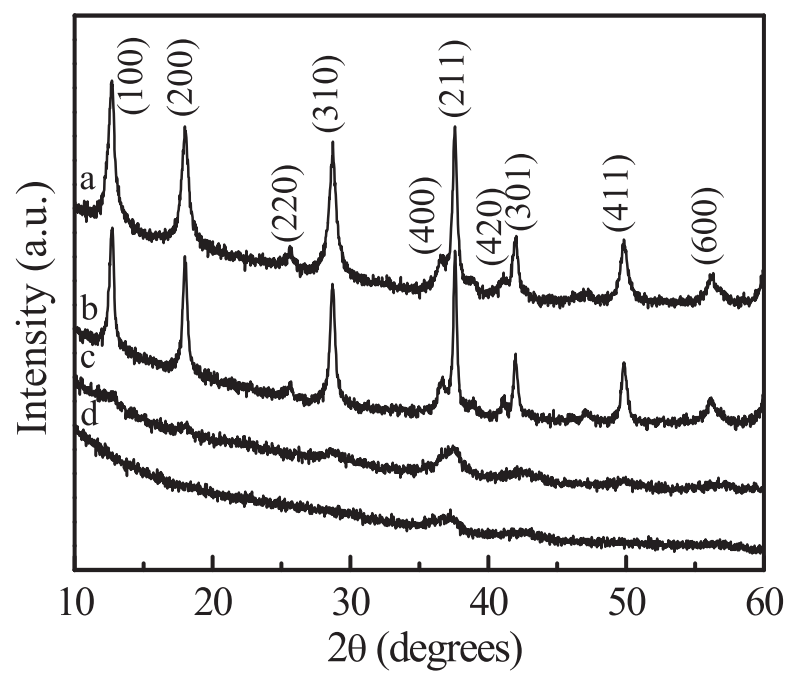

Fig. 2. XRD patterns of different samples: (a) OMS-2, (b) $\mathrm{Ce}(0.06)-\mathrm{OMS}-2$, (c) $\mathrm{Ce}(0.48)-O M S-2$, and (d) $\mathrm{Ce}(0.96)-O M S-2$.

between 1300 and $1500 \mathrm{~cm}^{-1}$ attributed to $\mathrm{Ce}-\mathrm{O}$ bonds [20] were detected, indicating no segregated cerium oxide impurities existed. The morphology change, the broadened XRD peaks and the FTIR spectroscopy studies revealed that Ce was incorporated into the framework of $\mathrm{Ce}(0.48)-\mathrm{OMS}-2$. Theoretically, $\mathrm{Ce}^{3+}(0.1034 \mathrm{~nm})$ or $\mathrm{Ce}^{4+}(0.094 \mathrm{~nm})$ was easier to enter the tunnel structure of OMS-2 to exchange $\mathrm{K}^{+}$, owing to the smaller ionic radius of $\mathrm{Ce}^{3+}$ or $\mathrm{Ce}^{4+}$ than that of $\mathrm{K}^{+}(0.133 \mathrm{~nm})[19,21,22]$. XPS analysis showed that the surface atomic ratio of Ce to Mn was 0.14 , while the bulk atomic ratio of Ce to $\mathrm{Mn}$ was about 0.41 . Moreover, the bulk K/Mn molar ratio of Ce(0.48)-OMS-2 was significantly lower than that of OMS-2 (Table 1 ). The results confirmed that the doped Ce mainly entered the tunnel structure of OMS-2 instead of $\mathrm{K}^{+}$. Therefore, Ce mainly 
Table 1

Bulk K, Mn, and Ce composition in the OMS-2 and Ce(0.48)-OMS-2 samples.

\begin{tabular}{|c|c|c|c|c|c|}
\hline \multirow[t]{2}{*}{ Sample } & \multicolumn{3}{|c|}{ Molar fraction (\%) } & \multicolumn{2}{|c|}{ Molar ratios } \\
\hline & $\mathrm{K}$ & $\mathrm{Mn}$ & $\mathrm{Ce}$ & $\mathrm{K} / \mathrm{Mn}$ & $\mathrm{Ce} / \mathrm{Mn}$ \\
\hline OMS-2 & 11.10 & 88.90 & - & 0.12 & - \\
\hline $\mathrm{Ce}(0.48)-\mathrm{OMS}-2$ & 2.40 & 69.45 & 28.15 & 0.034 & 0.41 \\
\hline
\end{tabular}

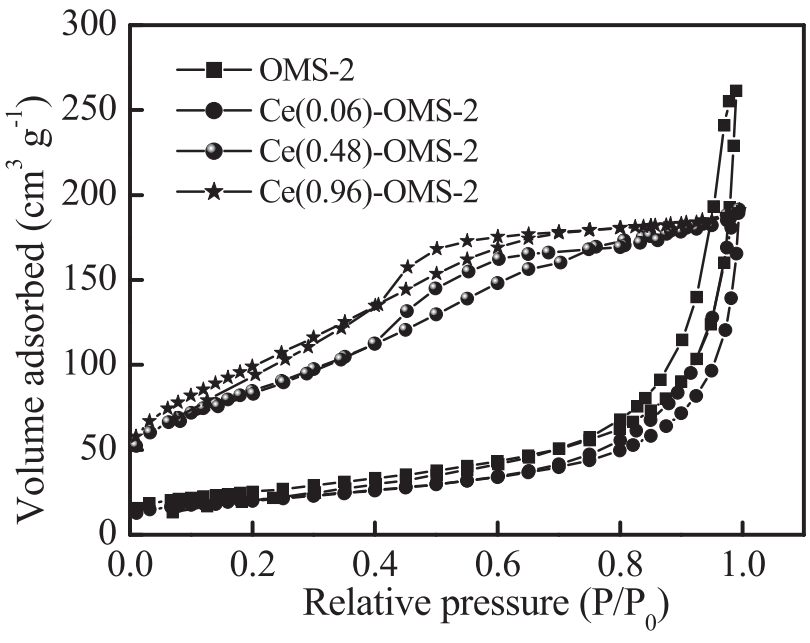

Fig. 3. $\mathrm{N}_{2}$ adsorption/desorption isotherms of different samples.

entered the tunnel structure and was partly incorporated into the framework of OMS-2 to replace K and Mn, respectively.

The $\mathrm{N}_{2}$ adsorption/desorption isotherms of the OMS-2 and CeOMS-2 samples are shown in Fig. 3. All the samples exhibited type IV isotherms, indicative of a solid mesoporous structure. Except for the difference that the isotherms of OMS-2 and $\mathrm{Ce}(0.06)-O M S-2$ were with a $\mathrm{H} 3$ hysteresis loop associated with rod-like fibers given rise to narrow slit porous shape, while those of $\mathrm{Ce}(0.48)-O M S-2$ and $\mathrm{Ce}(0.96)-\mathrm{OMS}-2$ were with a $\mathrm{H} 2$ hysteresis loop corresponding to pores with narrow necks and wider bodies [23]. The BET surface area followed the order of OMS-2 $\left(72 \mathrm{~m}^{2} \mathrm{~g}^{-1}\right)<\mathrm{Ce}(0.06)-O M S-2\left(90 \mathrm{~m}^{2} \mathrm{~g}^{-1}\right)<\mathrm{Ce}(0.48)$-OMS$2\left(304 \mathrm{~m}^{2} \mathrm{~g}^{-1}\right)<\mathrm{Ce}(0.96)-\mathrm{OMS}-2\left(366 \mathrm{~m}^{2} \mathrm{~g}^{-1}\right)$, indicating that the doping of Ce significantly increased the surface area, which was likely due to the reduction of fiber length with increase of Ce content. Specially, the specific surface area of $\mathrm{Ce}(0.48)-\mathrm{OMS}-2$ was 4.2 times larger than that of undoped OMS-2. However, the similar adsorption amount was achieved on $\mathrm{Ce}(0.48)-\mathrm{OMS}-2$ and OMS2 (Fig. 4), indicating the increase of specific surface area by the introduction of Ce probably enhanced surface reactivity instead of adsorption.

As shown in Fig. $5 \mathrm{~A}$, the Mn $2 \mathrm{p}_{3 / 2}$ peaks of OMS- 2 and $\mathrm{Ce}(0.48)-$ OMS-2 were at $641.8 \mathrm{eV}$ and $642.4 \mathrm{eV}$ for $\mathrm{Mn}^{3+}$ and $\mathrm{Mn}^{4+}$ [24]. The experimental and fitted $\mathrm{Ce} 3 \mathrm{~d}$ spectra of $\mathrm{Ce}(0.48)-\mathrm{OMS}-2$ were presented in Fig. 5B. The surface atom ratio of $\mathrm{Ce}^{3+}$ to $\mathrm{Ce}^{4+}$ was 1.13 , where $\mathrm{Ce}^{3+}=\left(u^{\prime}+u_{0}+v^{\prime}+v_{0}\right)$ and $\mathrm{Ce}^{4+}=\left(u^{\prime \prime \prime}+u^{\prime \prime}+u+v^{\prime \prime \prime}+v^{\prime \prime}+v\right)$ [24]. The surface average oxidation state (AOS) of Mn was estimated based on the formula: AOS $=8.956-1.126(\Delta E)$ [25], where $\Delta E$ is the Mn 3s multiplet splitting values (Fig. 5C). The surface AOS of OMS-2 and Ce(0.48)-OMS-2 was 3.8 and 3.7, respectively. The result suggested that $\mathrm{Mn}$ (IV) was dominant in both materials, and the influence of Ce incorporation on the AOS of Mn was not significant. In addition, $\mathrm{O} 1 \mathrm{~s}$ spectra for OMS-2 and $\mathrm{Ce}(0.48)-O M S-2$ were both fitted roughly with two peaks (Fig. 5D), $\mathrm{O}_{\mathrm{I}}$ and $\mathrm{O}_{\mathrm{II}}$, representing lattice oxide and a defect-oxide or hydroxyl-like group, respectively [26]. The atom ratio of $\mathrm{O}_{\text {I }}$ to $\mathrm{O}_{\text {II }}$ was 2.18 and 1.26 for OMS-2 and $\mathrm{Ce}(0.48)$-OMS-2, respectively, indicating that the doping of $\mathrm{Ce}$

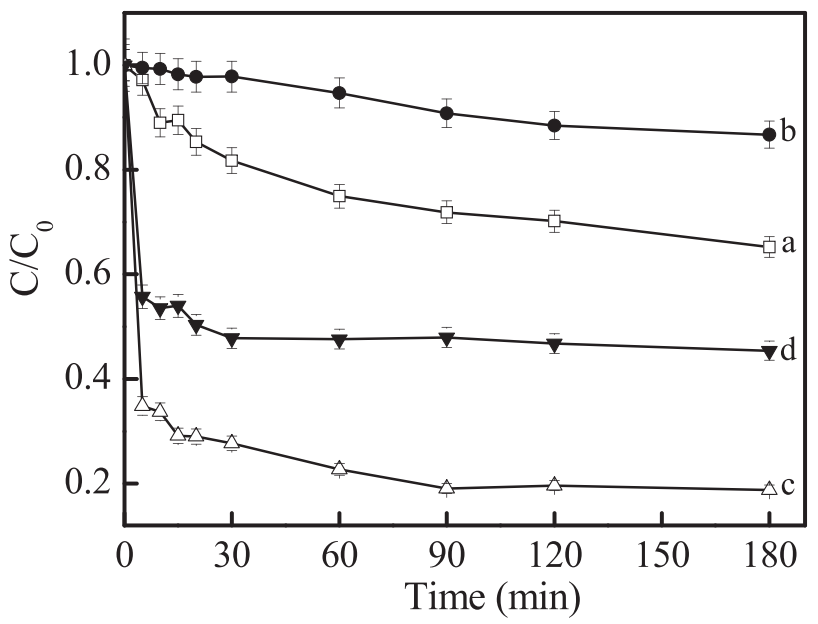

Fig. 4. The contributions of adsorption and oxidation for the CIP $\left(10 \mathrm{mg} \mathrm{L}^{-1}\right)$ removal in different suspensions $\left(0.1 \mathrm{~g} \mathrm{~L}^{-1}\right)$ : (a) OMS-2, (b) OMS-2 + oxalic acid, (c) $\mathrm{Ce}(0.48)$ OMS-2, and (d) Ce(0.48)-OMS-2 + oxalic acid.

Table 2

Quantitative results of $\mathrm{O}_{2}$-TPD.

\begin{tabular}{llll}
\hline Sample & $\mathrm{SLO}\left(\mu \mathrm{molg}^{-1}\right)$ & $\mathrm{SSO}_{\text {lat }}\left(\mu \mathrm{molg}^{-1}\right)$ & $\mathrm{BO}_{\text {lat }}\left(\mu \mathrm{molg}^{-1}\right)$ \\
\hline OMS-2 & 18 & 132 & 74 \\
$\mathrm{Ce}(0.48)-O M S-2$ & 36 & 156 & 31 \\
\hline
\end{tabular}

increased the oxygen defects of OMS-2. To identify and quantify different oxygen species, $\mathrm{O}_{2}$-TPD analysis was conducted. The $\mathrm{O}_{2}$-TPD spectra could be separated into three regions (Fig. 6): low temperature $\left(\mathrm{LT},<400^{\circ} \mathrm{C}\right)$, medium temperature (MT, $\left.400-700^{\circ} \mathrm{C}\right)$, and high temperature $\left(\mathrm{HT},>700^{\circ} \mathrm{C}\right)[15]$. The LT peaks were ascribed to surface labile oxygen (SLO) desorption, including chemisorbed oxygen molecule and surface lattice oxygen (Olat) [27]. The MT peaks were assigned to the evolution of sub-surface Olat (SSOlat), and the HT peaks corresponded to the evolution of bulk Olat (BOlat). The amount of desorbed $\mathrm{O}_{2}$ was estimated by integrating the area of $\mathrm{O}_{2}$-TPD curves (Table 2). Quantification results indicated that SLO of $\mathrm{Ce}(0.48)-O M S-2$ doubled than that of OMS-2, SSOlat also increased, and BOlat significantly decreased after Ce doping. The increase of SLO could be explained as the increase of surface defect created more sites for the dissociative adsorption of oxygen molecule. The significant decrease of BOlat indicated the enhanced mobility of bulk Olat after the doping of $\mathrm{Ce}$, probably due to the formation of oxygen vacancies which facilitated the transportation of Olat from bulk to surface [28]. The existence of the redox couple $\mathrm{Ce}^{3+} / \mathrm{Ce}^{4+}$ in $\mathrm{Ce}(0.48)-O M S-2$ also enhanced the formation of oxygen vacancies $[29,30]$.

\subsection{Catalytic degradation of CIP in Ce-OMS-2 suspension}

OMS-2 and Ce-OMS-2 were applied for the catalytic removal of $\mathrm{CIP}$ at room temperature and neutral $\mathrm{pH}$. The effect of Ce doping on the activity of catalysts is shown in Fig. 7A. Less than $35 \%$ of CIP was degraded after reaction for $3 \mathrm{~h}$ in OMS-2 suspension. The degradation of CIP was slightly increased in $\mathrm{Ce}(0.06)-\mathrm{OMS}-2$ suspension. 

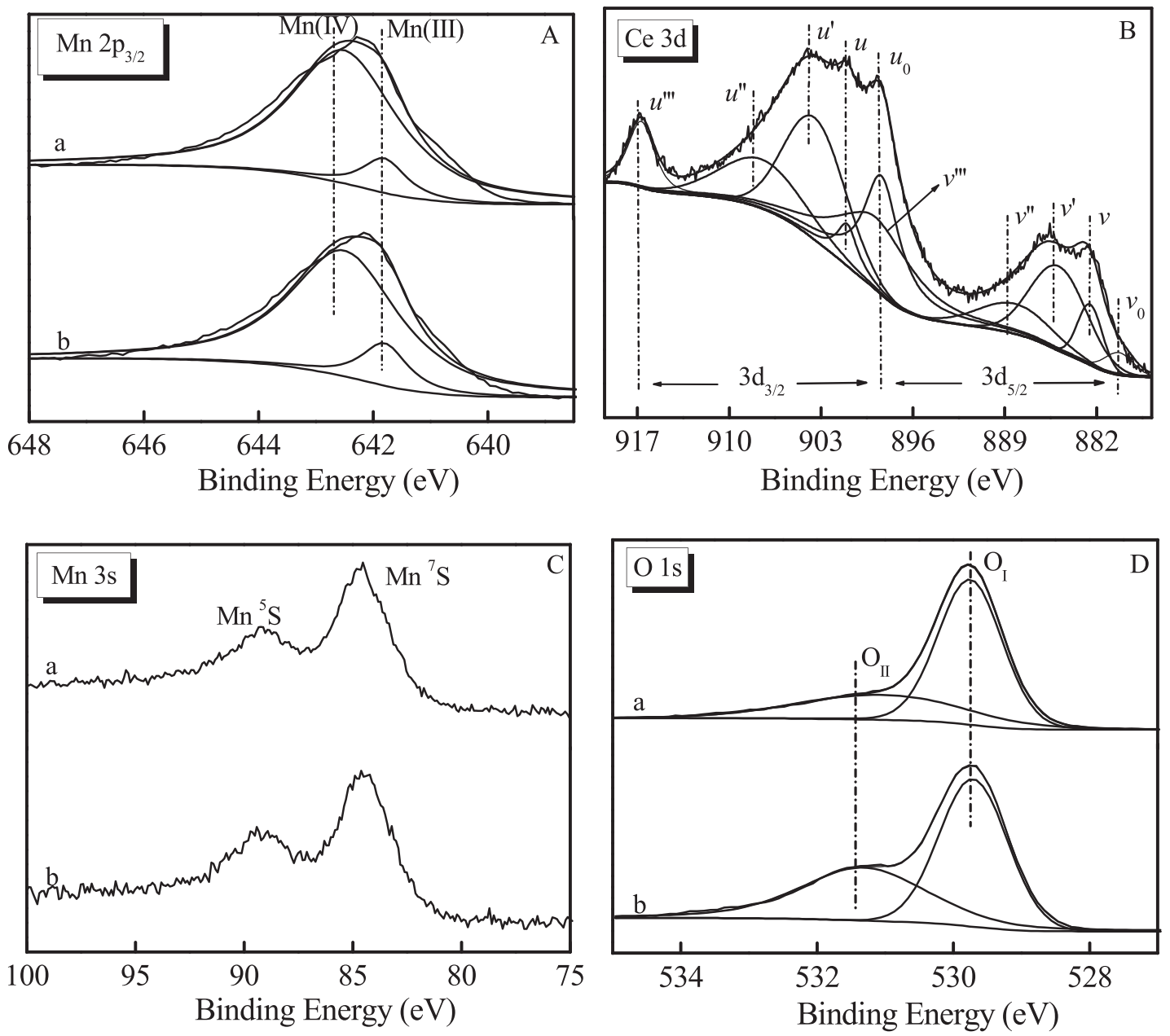

Fig. 5. XPS spectra of (a) OMS-2 and (b) Ce(0.48)-OMS-2: (A) Mn 2p $\mathrm{p}_{3 / 2}$, (B) Ce 3d, (C) Mn 3s, (D) O 1s of Ce(0.48)-OMS-2.

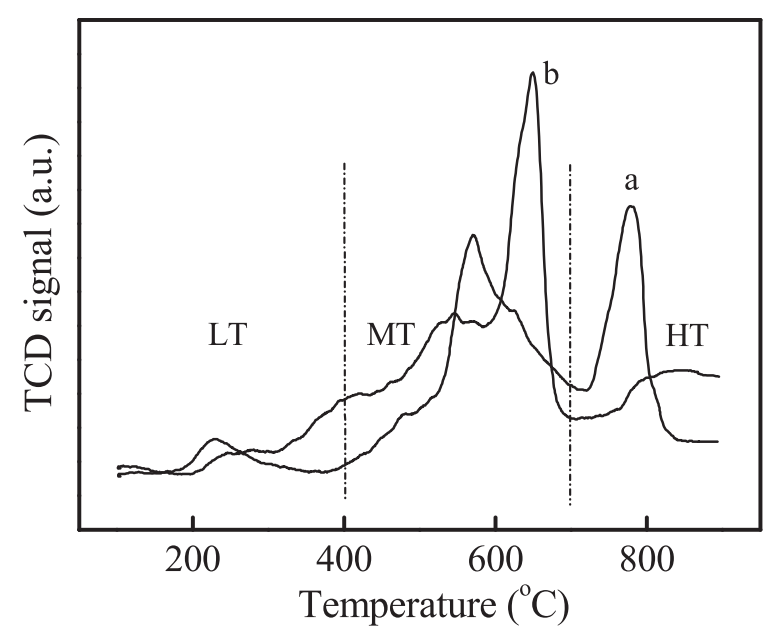

Fig. 6. $\mathrm{O}_{2}$-TPD profiles of different samples: (a) OMS-2, (b) $\mathrm{Ce}(0.48)-\mathrm{OMS}-2$.

Increasing $\mathrm{Ce} / \mathrm{Mn}$ to 0.48 in the preparation, the degradation rate of CIP significantly increased and up to $81 \%$ of CIP was removed within $3 \mathrm{~h}$. With a higher Ce/Mn molar ratio of 0.96 , the degradation of CIP was not significantly increased. During CIP degradation, the concentration of dissolved metals was determined in Fig. 7B. After $180 \mathrm{~min}$ reaction, the amount of $\mathrm{Mn}$ (II) release followed the order of OMS-2 $\left(0.012 \mathrm{mg} \mathrm{L}^{-1}\right)<\mathrm{Ce}(0.48)-O M S-2\left(0.031 \mathrm{mg} \mathrm{L}^{-1}\right)<\mathrm{Ce}(0.06)-$ OMS-2 $\left(0.079 \mathrm{mg} \mathrm{L}^{-1}\right)<\mathrm{Ce}(0.96)-O M S-2\left(0.256 \mathrm{mg} \mathrm{L}^{-1}\right)$, suggesting that there existed an optimal Ce/Mn molar ratio in the preparation process for the stability of Ce-OMS-2. The cycle tests exhibited that the conversion of CIP decreased by $7 \%$ in the sixth cycle of $\mathrm{Ce}(0.48)-\mathrm{OMS}-2$ and remained at approximately $74 \%$ within $180 \mathrm{~min}$ in the continuous cycles (Fig. S3). Furthermore, no significant change was observed in the XPS spectra of surface Mn, $\mathrm{Ce}$ and $\mathrm{O}$ of $\mathrm{Ce}(0.48)-\mathrm{OMS}-2$ after reaction (Fig. S4). The Mn $2 \mathrm{p}_{3 / 2}$ peaks of $\mathrm{Ce}(0.48)-\mathrm{OMS}-2$ were at $641.8 \mathrm{eV}$ and $642.4 \mathrm{eV}$ for $\mathrm{Mn}^{3+}$ and $\mathrm{Mn}^{4+}$ before reaction and remained intact after reaction. The AOS of Mn before and after reaction was 3.7 and 3.6, respectively. And the atom ratio of $\mathrm{O}_{\mathrm{I}}$ to $\mathrm{O}_{\text {II }}$ was 1.26 and 1.22 for $\mathrm{Ce}(0.48)$-OMS2 before and after reaction, respectively. The results indicated that the catalyst had an excellent stability. The high activity and stability of $\mathrm{Ce}(0.48)-O M S-2$ microspheres were probably related to its well-organized morphology and the changed surface properties. First, the much larger surface area of Ce(0.48)-OMS-2 $\left(304 \mathrm{~m}^{2} \mathrm{~g}^{-1}\right)$ than OMS-2 $\left(72 \mathrm{~m}^{2} \mathrm{~g}^{-1}\right)$ enhanced its surface reactivity. Second, the considerable oxygen defects after Ce doping were at least in part responsible for better activity of $\mathrm{Ce}(0.48)$-OMS-2. Third, the doubled surface labile oxygen probably reoxidized $\mathrm{Mn}(\mathrm{II})$, which generated from the reduction of $\mathrm{Mn}(\mathrm{IV})$ in $\mathrm{Ce}(0.48)-\mathrm{OMS}-2$ during CIP oxidation, and thus inhibited the release of $\mathrm{Mn}(\mathrm{II})$, resulting in the excellent stability of $\mathrm{Ce}(0.48)$-OMS-2.

\subsection{Pathways of CIP degradation in Ce-OMS-2 suspension}

The CIP degradation intermediates in $\mathrm{Ce}(0.48)-O M S-2$ suspension were analyzed to understand its fate. $\mathrm{F}^{-}$was not detected by 


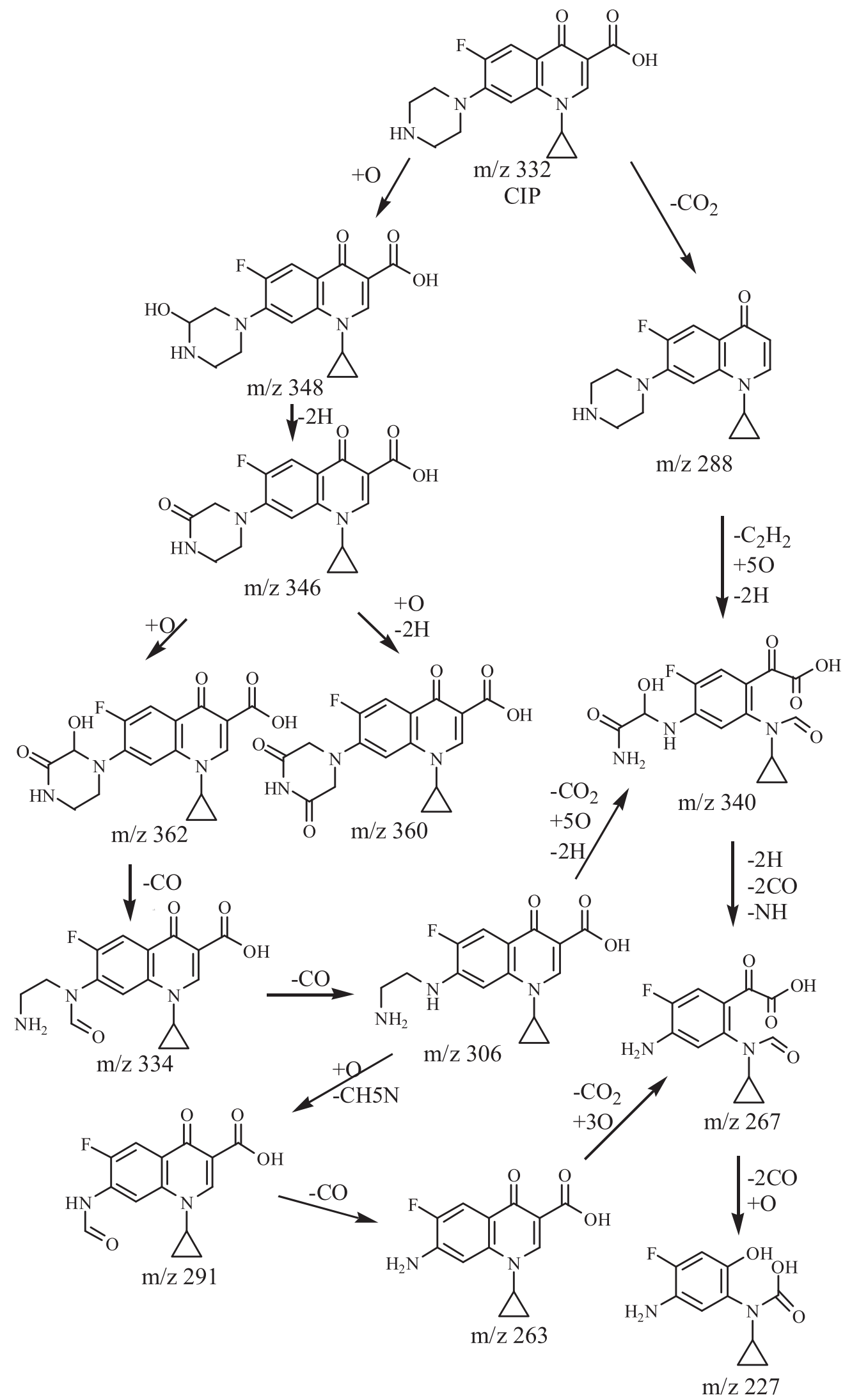

Scheme 1. Suggested pathways for CIP degradation in Ce(0.48)-OMS-2 suspension.

IC, indicating the $\mathrm{C}-\mathrm{F}$ bond was intact. Twelve intermediate products of CIP were identified by LC-MS in Table S1 with proposed molecular formulas and structures on the basis of MassFragment software analysis. The presence of eight products with molecular ions of $\mathrm{m} / \mathrm{z} 348,346,360,362,334,306,291$ and 263 suggested the oxidative degradation of the piperazine ring of CIP. Specially, the 

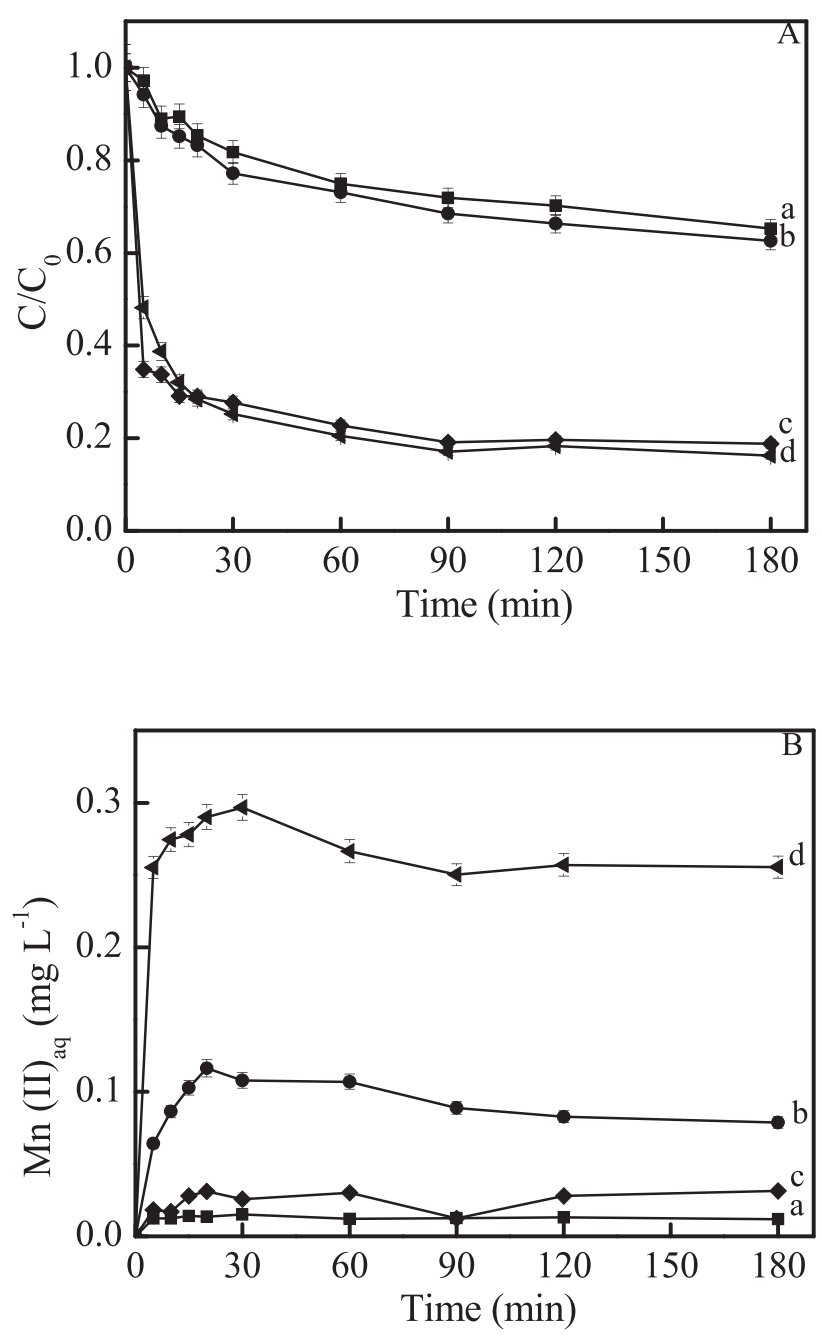

Fig. 7. (A) The oxidation of $\mathrm{CIP}\left(10 \mathrm{mg} \mathrm{L}^{-1}\right)$ and (B) the releasing of $\mathrm{Mn}(\mathrm{II})$ in different suspensions (0.1 g L $\left.{ }^{-1}\right)$ : (a) OMS-2, (b) Ce(0.06)-OMS-2, (c) Ce(0.48)-OMS-2, and (d) Ce(0.96)-OMS-2.

appearance of other four products with molecular ions of $\mathrm{m} / \mathrm{z} 288$, 340,267 and 227 indicated the elimination of the carboxylic and keto groups at the quinolone moiety which were in part responsible for the antibacterial activity of CIP [31]. Therefore, CIP degradation in $\mathrm{Ce}(0.48)$-OMS-2 suspension at neutral $\mathrm{pH}$ may be promising for reduction of bacterial resistance against quinolones in contaminated water. Based on the identified intermediate products, a reaction pathway for CIP oxidation was proposed in Scheme 1. Stepwise cleavage of the piperazine ring started with the introduction of a hydroxyl group ( $\mathrm{m} / \mathrm{z} 348$ ) followed by oxidation to the keto-derivative ( $\mathrm{m} / \mathrm{z} 346)$. An additional sequence of incorporation of an oxygen atom resulted in the formation of the hydroxylketoderivative $(\mathrm{m} / \mathrm{z} 362)$ and diketo-derivative $(\mathrm{m} / \mathrm{z} 360)$. Subsequent loss of CO results in opening of the piperazinyl ring (m/z 334). A second loss of a CO molecule leads to the formation of desethylene ciprofloxacin ( $\mathrm{m} / \mathrm{z} 306)$. The further oxidation of desethylene ciprofloxacin generated a compound ( $\mathrm{m} / \mathrm{z} 291)$ with a keto group by loss of a $\mathrm{N}$ atom. The formation of aniline $(\mathrm{m} / \mathrm{z} 263)$ by further decarbonylation indicated the complete elimination of the piperazine ring. On the other hand, the destruction of the quinolone moiety involved the direct decarboxylation ( $\mathrm{m} / \mathrm{z} 288)$ and the breakdown of the carbon-carbon double bond adjacent to the carboxylic acid group ( $\mathrm{m} / \mathrm{z} 340, \mathrm{~m} / \mathrm{z} 267$ and $\mathrm{m} / \mathrm{z} 227)$. Additionally, the generation of the short-chain organic acids (Fig. 8), acetic acid, formic acid and oxalic acid, further confirmed the deep oxidation of CIP in

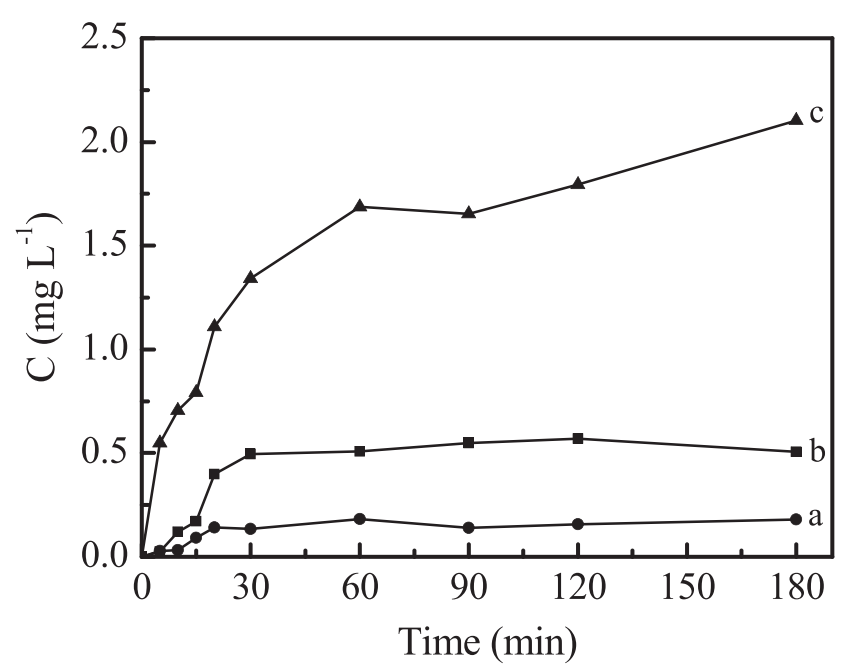

Fig. 8. The formation of organic acids during CIP $\left(10 \mathrm{mg} \mathrm{L}^{-1}\right)$ oxidation in $\mathrm{Ce}(0.48)$ OMS-2 suspension $\left(0.1 \mathrm{~g} \mathrm{~L}^{-1}\right)$ : (a) acetic acid, (b) formic acid, and (c) oxalic acid.

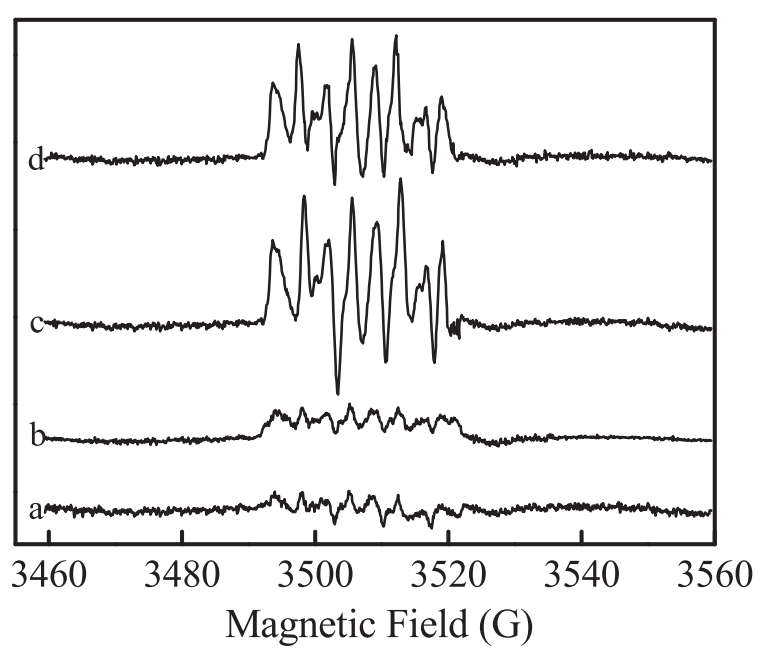

Fig. 9. DMPO spin-trapping ESR spectra recorded in different suspensions under air: (a) OMS-2, (b) Ce(0.06)-OMS-2, (c) Ce(0.48)-OMS-2, and (d) Ce(0.96)-OMS-2.

$\mathrm{Ce}(0.48)$-OMS-2 suspension. In contrast, only the piperazine moiety of CIP was destructed in $\mathrm{MnO}_{2}$ suspensions, due to the oxidation of $\mathrm{Mn}(\mathrm{IV})$ [32]. The higher oxidation ability of Ce-OMS-2 than $\mathrm{MnO}_{2}$ indicated the possible existence of other active oxygen species.

\subsection{Reaction mechanism}

The reactive oxygen species (ROS) in different catalyst suspensions were detected by the ESR spin-trapping technique. As shown in Fig. 9, the ESR signals in all the OMS-2 and CeOMS-2 suspensions corresponded to superoxide radical $\left(\mathrm{O}_{2}{ }^{-}\right)$ [33]. The intensities of the signals increased with increase of Ce doping content, and reached the maximum in $\mathrm{Ce}(0.48)$ OMS-2 suspension, then slightly decreased with further increase of Ce dosage in the preparation, which agreed with the degradation of CIP. Both Ce(0.48)-OMS-2 and Ce(0.96)-OMS-2 exhibited higher activity than OMS-2 and Ce(0.06)-OMS-2, suggesting that the activity of Ce-doped OMS- 2 was related to the formed $\mathrm{O}_{2}{ }^{-}{ }^{-}$. Furthermore, the degradation of CIP was partly inhibited with the addition of $\mathrm{O}_{2}{ }^{-}$- scavenger $p$-benzoquinone in $\mathrm{Ce}(0.48)$-OMS2 suspension (Fig. S5), confirming that the $\mathrm{O}_{2}{ }^{-}$- radicals were the active species involved in the process of CIP degradation. $\mathrm{Ce}(0.48)$ OMS-2 exhibited similar activity at $\mathrm{N}_{2}$ and air atmosphere for the 

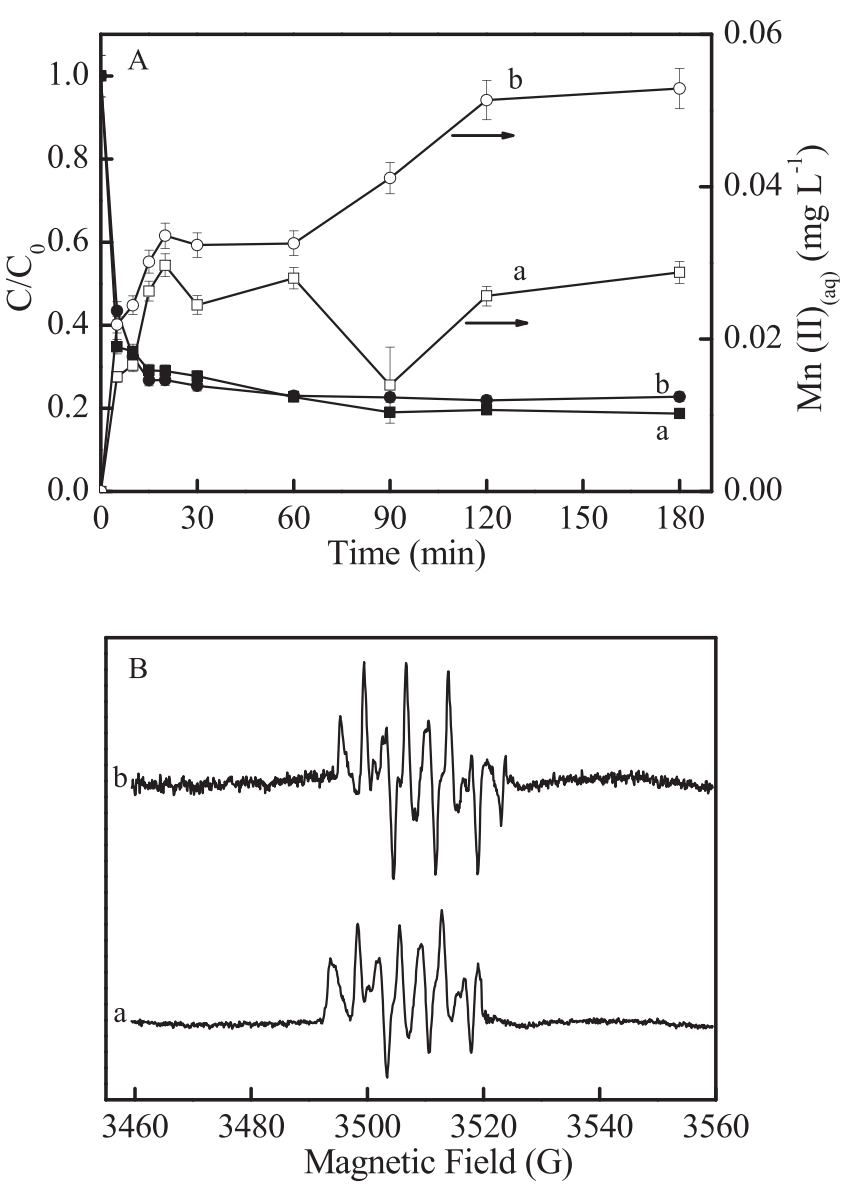

Fig. 10. (A) The oxidation of CIP $\left(10 \mathrm{mg} \mathrm{L}^{-1}\right)$ and the releasing of $\mathrm{Mn}(\mathrm{II})$, and (B) DMPO spin-trapping ESR spectra recorded in $\mathrm{Ce}(0.48)-\mathrm{OMS}-2$ suspension $\left(0.1 \mathrm{~g} \mathrm{~L}^{-1}\right)$ under different atmosphere: (a) air, (b) $\mathrm{N}_{2}$.

degradation of CIP and the generation of $\mathrm{O}_{2}{ }^{-}$, but the release of $\mathrm{Mn}(\mathrm{II})$ was higher at $\mathrm{N}_{2}$ atmosphere (Fig. 10). The results suggested that $\mathrm{O}_{2}$ in water did not affect the reaction activity and the formation of $\mathrm{O}_{2}{ }^{-}$, while the reoxidation of $\mathrm{Mn}(\mathrm{II})$ was related to $\mathrm{O}_{2}$, not $\mathrm{O}_{2}{ }^{-}$. Furthermore, the effect of surface labile oxygen of $\mathrm{Ce}(0.48)-\mathrm{OMS}-2$ was examined. In the experiments, $\mathrm{N}_{2}$ was constantly bubbled into $\mathrm{Ce}(0.48)$-OMS-2 suspenion for $24 \mathrm{~h}$ to remove surface labile oxygen of the material, which was denoted as $\mathrm{Ce}(0.48)-O M S-2-\mathrm{N}_{2}-24 \mathrm{~h}$. Subsequently, one part was dried at $100{ }^{\circ} \mathrm{C}$ in air, which was designated as $\mathrm{Ce}(0.48)-\mathrm{OMS}-2-\mathrm{N}_{2}-24 \mathrm{~h}-$
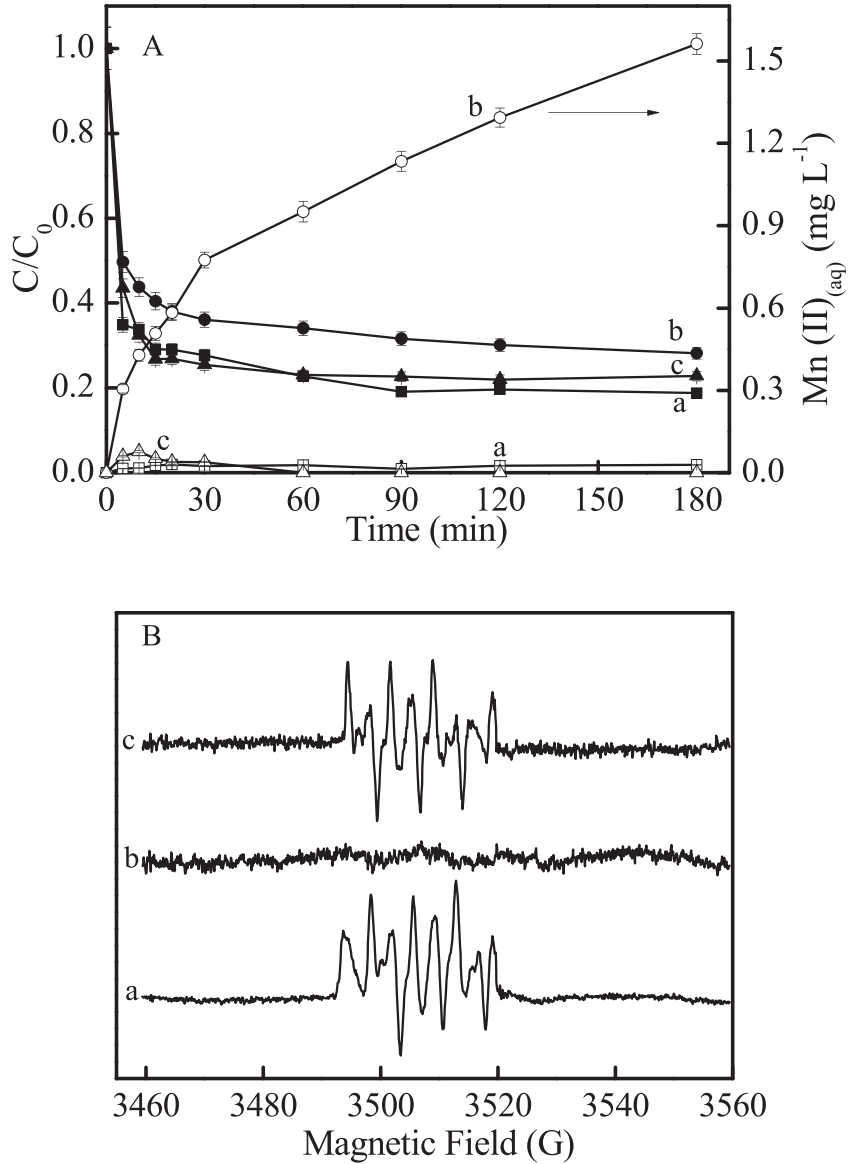

Fig. 11. (A) The oxidation of CIP $\left(10 \mathrm{mg} \mathrm{L}^{-1}\right)$ and the releasing of $\mathrm{Mn}(\mathrm{II})$, and (B) DMPO spin-trapping ESR spectra recorded in different suspensions: (a) fresh $\mathrm{Ce}(0.48)-\mathrm{OMS}-2$, (b) $\mathrm{Ce}(0.48)-\mathrm{OMS}-2-\mathrm{N}_{2}-24 \mathrm{~h}$, (c) $\mathrm{Ce}(0.48)-\mathrm{OMS}-2-\mathrm{N}_{2}-24 \mathrm{~h}-100^{\circ} \mathrm{C}$.

$100^{\circ} \mathrm{C}$. Obviously, the activity of $\mathrm{Ce}(0.48)-\mathrm{OMS}-2$ decreased and the release of $\mathrm{Mn}$ (II) greatly increased after $\mathrm{N}_{2}$ treatment for $24 \mathrm{~h}$, while $\mathrm{Ce}(0.48)-O M S-2$ exhibited original activity and no significant $\mathrm{Mn}(\mathrm{II})$ releasing occurred during the reaction after the $\mathrm{Ce}(0.48)$ OMS-2- $\mathrm{N}_{2}-24 \mathrm{~h}$ was dried at $100^{\circ} \mathrm{C}$ in air (Fig. 11A). Similarly, the $\mathrm{O}_{2}{ }^{-}$- signals disappeared in $\mathrm{Ce}(0.48)-\mathrm{OMS}-2-\mathrm{N}_{2}-24 \mathrm{~h}$ suspension, while they appeared again in $\mathrm{Ce}(0.48)-\mathrm{OMS}-2-\mathrm{N}_{2}-24 \mathrm{~h}-100{ }^{\circ} \mathrm{C}$ suspension (Fig. 11B). The results indicated that the inhibition of $\mathrm{Mn}(\mathrm{II})$ release and the generation of $\mathrm{O}_{2}{ }^{-}$- depended on the existence of

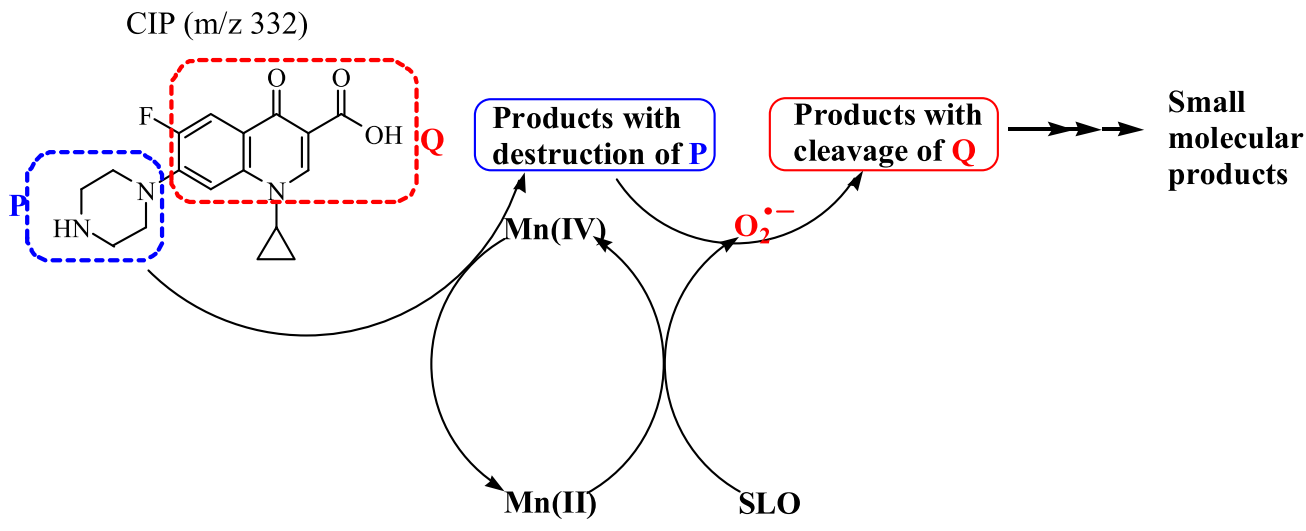

Scheme 2. Proposed mechanism for the degradation of CIP and the inhibition of Mn(II) release on the micro-interface of Ce(0.48)-OMS-2. 
surface labile oxygen on $\mathrm{Ce}(0.48)-\mathrm{OMS}-2$. It has been verified that the surface labile oxygen of oxides enhanced the surface electron transfer [34,35], and the complexes of dioxygen with reduced manganese may be considered to produce activated oxygen [36]. These results indicated that the $\mathrm{O}_{2}{ }^{-}$- was produced, and the $\mathrm{Mn}(\mathrm{II})$ release was inhibited by the redox reaction of surface labile oxygen with $\mathrm{Mn}(\mathrm{II})$ on the surface of $\mathrm{Ce}(0.48)-\mathrm{OMS}-2$. In combination with the intermediates analysis, the high oxidation ability of $\mathrm{Mn}(\mathrm{IV})$ and the formed $\mathrm{O}_{2}{ }^{-}$- resulted in the destruction of the piperazine ring and quinolone moiety of CIP.

From the above results, the mechanism as shown in Scheme 2 can be proposed for the degradation of CIP and the inhibition of $\mathrm{Mn}(\mathrm{II})$ release on the micro-interface of $\mathrm{Ce}(0.48)-\mathrm{OMS}-2$. First, CIP was oxidized by $\mathrm{Mn}(\mathrm{IV})$ on the surface of $\mathrm{Ce}(0.48)$-OMS-2, followed by the release of organic oxidation products and the generation of $\mathrm{Mn}(\mathrm{II})$. Then, the reoxidation of $\mathrm{Mn}$ (II) by SLO occurred on the micro-interface, and simultaneously, $\mathrm{O}_{2}{ }^{-}$- was produced to attack the quinone moiety of CIP. The synergistic effect of $\mathrm{Mn}(\mathrm{IV})$ and $\mathrm{O}_{2}{ }^{-}$ led to the degradation of CIP into small molecular products. Moreover, the release of $\mathrm{Mn}(\mathrm{II})$ was inhibited in the electron transfer process.

\section{Conclusions}

Ce-OMS-2 was successfully prepared by a reflux method. The catalyst at a $\mathrm{Ce} / \mathrm{Mn}$ molar ratio of 0.48 exhibited the best catalytic activity and stability for the degradation of CIP at room temperature and neutral $\mathrm{pH}$. The characterization results comfirmed that the doping of Ce changed the microstructure of OMS-2 from fibrous rods to microspheres, and increased the specific surface area and the amount of SLO. Therefore, the surface reactivity was enhanced, the release of $\mathrm{Mn}(\mathrm{II})$ was inhibited by the oxidation of SLO, and $\mathrm{O}_{2}{ }^{-}$- was generated on the micro-interface of $\mathrm{Ce}(0.48)-\mathrm{OMS}-2$. The synergistic effect of $\mathrm{Mn}(\mathrm{IV})$ and $\mathrm{O}_{2}{ }^{-}-$led to the destruction of the piperazine ring and quinolone moiety of CIP. The high activity and exellent stability under ambient conditions suggest that $\mathrm{Ce}(0.48)$ OMS-2 is a promising catalyst for removal of organic pollutants in wastewater.

\section{Acknowledgment}

This work was supported by the National Natural Science Foundation of China (Grant Nos. 51278527, 21125731, 51138009, $51538013,21407165)$.

\section{Appendix A. Supplementary data}

Supplementary data associated with this article can be found, in the online version, at http://dx.doi.org/10.1016/j.apcatb.2015. 08.029.

\section{References}

[1] T.C. An, H.Y, G.Y.L, W.H. Song, W.J. Cooper, X.P. Nie, Appl. Catal. B Environ. 94 (2010) 288-294

[2] X.X. Wei, J.W. Chen, Q. Xie, S.Y. Zhang, L.K. Ge, X.L. Qiao, Environ. Sci. Technol, 47 (2013) 4284-4290.

[3] D.G.J. Larsson, C. de Pedro, N. Paxeus, J. Hazard. Mater. 148 (2007) 751-755.

[4] R. Kumar, S. Sithambaram, S.L. Suib, J. Catal. 262 (2009) 304-313.

[5] F. Schurz, J.M. Bauchert, T. Merker, T. Schleid, H. Hasse, R. Glaeser, Appl. Catal. A 355 (2009) 42-49.

[6] S.L. Suib, Acc. Chem. Res. 41 (2008) 479-487.

[7] X.F. Shen, Y.S. Ding, J. Liu, Z.H. Han, J.I. Budnick, W.A. Hines, S.L. Suib, J. Am. Chem. Soc. 127 (2005) 6166-6167.

[8] S.L. Suib, J. Mater. Chem. 18 (2008) 1623-1631.

[9] M. Sun, L. Yu, F. Ye, G. Diao, Q. Yu, Z. Hao, Y. Zheng, L. Yuan, Chem. Eng. J. 220 (2013) 320-327.

[10] X. Xiao, S.P. Sun, M. McBride, A. Lemley, Environ. Sci. Pollut. R. 20 (2013) 10-21.

[11] X.S. Liu, Z.N. Jin, J.Q. Lu, X.X. Wang, M.F. Luo, Chem. Eng. J. 162 (2010) 151-157.

[12] C.K. King'ondu, N. Opembe, C.H. Chen, K. Ngala, H. Huang, A. Iyer, H.F. Garcés, S.L. Suib, Adv. Funct. Mater. 21 (2011) 312-323.

[13] Y. Yang, J. Huang, S.Z. Zhang, S.W. Wang, S.B. Deng, B. Wang, G. Yu, Appl. Catal. B Environ. 150-151 (2014) 167-187.

[14] C.K. King'ondu, N. Opembe, C.H. Chen, K. Ngala, H. Huang, A. Iyer, H.F. Garcés, S.L. Suib, Adv. Funct. Mater. 21 (2011) 312-323.

[15] R. Jothiramalingam, B. Viswanathan, T.K. Varadarajan, Catal. Commun. 6 (2005) 41-45.

[16] Y.Z. Li, Z.Y. Fan, J.W. Shi, Z.Y. Liu, J.W. Zhou, W.F. Shangguan, Catal. Today 256 (2015) $178-185$.

[17] L. Sun, Q. Cao, B. Hu, J. Li, J. Hao, G. Jing, X. Tang, Appl. Catal. A Gen. 393 (2011) 323-330.

[18] J.T. Hou, L.L. Liu, Y.Z. Li, M.Y. Mao, H.Q. Lv, X.J. Zhao, Environ. Sci. Technol. 47 (2013) 13730-13736.

[19] M. Ousmane, G. Perrussel, Z. Yan, M. Clacens, F. De Campo, M. Pera-Titus, J. Catal. 309 (2014) 439-452.

[20] M. Palard, J. Balencie, A. Maguer, J.F. Hochepied, Mater. Chem. Phys. 120 (2010) 79-88.

[21] G.D. Yadav, A.R. Yadav, J. Mol. Catal. A Chem. 380 (2013) 70-77.

[22] Z.Y. Cai, M.Q. Zhu, J. Chen, Y.Y. Shen, J. Zhao, Y. Tang, X.Z. Chen, Catal. Commun. 12 (2010) 197-201.

[23] M.L. García-Benjume, M.I. Espitia-Cabrera, M.E. Contreras-García, Int. J. Photoenergy 2012 (2012) 1-10.

[24] Z.Q. Zou, M. Meng, Y.Q. Zha, J. Phys. Chem. C 114 (2010) 468-477.

[25] V.R. Galakhov, M. Demeter, S. Bartkowski, M. Neumann, N.A. Ovechkina, E.Z. Kurmaev, N.I. Lobachevskaya, Y.M. Mukovskii, J. Mitchell, D.L. Ederer, Phys. Rev. B 65 (2002) 1131021-1131024.

[26] H. Chen, A. Sayari, A. Adnot, F. Larachi, Appl. Catal. B Environ. 32 (2001) 195-204.

[27] Y. Yang, J. Huang, S. Wang, S. Deng, B. Wang, G. Yu, Appl. Catal. B Environ. 142-143 (2013) 568-578.

[28] F.H. Niu, D.S. Zhang, L.Y. Shi, X.Q. He, H.R. Li, H.L. Mai, T.T. Yan, Mater. Lett. 63 (2009) 2132-2135

[29] D.S. Zhang, T.T. Yan, C.S. Pan, L.Y. Shi, J.P. Zhang, Mater. Chem. Phys. 113 (2009) 527-530.

[30] M. Škoda, M. Cabala, I. Matolínová, K.C. Prince, T. Skála, F. Šutara, et al., J. Chem. Phys. 130 (2009) 034703-034707.

[31] M. Mahdi-Ahmed, S. Chiron, J. Hazard. Mater. 265 (2014) 41-46

[32] H.C. Zhang, C.H. Huang, Environ. Sci. Technol. 39 (2005) 4474-4483.

[33] J. Tu, Z. Yang, C. Hu, J. Chem. Technol. Biotechnol. 90 (2015) 80-86.

[34] C.S. Liu, L.J. Zhang, C.H. Feng, C.A. Wu, F.B. Li, X.Z. Li, Environ. Chem. 6 (2009) 83-92.

[35] X.J. Li, C.S. Liu, F.B. Li, Y.T. Li, L.J. Zhang, C.P. Liu, Y.Z. Zhou, J. Hazard. Mater. 173 (2010) 675-681.

[36] Y.C. Son, V.D. Makwana, A.R. Howell, S.L. Suib, Angew. Chem. Int. Ed. 40 (2001) 4280-4283. 